\title{
Gratifications of digital media: A demographic view from four countries in south- east Asia
}

\author{
Hendy Kasima*, Edi Abdurachmana, Asnan Furinto ${ }^{a}$ and Wibowo Kosasiha
}

${ }^{a}$ Bina Nusantara University, Doctor of Research in Management, Jl. Kebon Jeruk Raya No.27, Jakarta Barat 11530, Indonesia

\begin{tabular}{l}
\hline C H R O N I C L E \\
\hline Article history: \\
Received: June 302019 \\
Received in revised format: July \\
292019 \\
Accepted: September 16, 2019 \\
Available online: \\
September 16, 2019 \\
\hline Keywords: \\
Obtained Gratification \\
Digital Media \\
Uses and Gratifications Theory \\
Southeast Asia
\end{tabular}
\section{A B S T R A C T}

The Gratification Obtained is an essential part of media studies. It analyzes the gratifications obtained by the media users. This paper reveals findings from observations towards the digital media users in four countries in Southeast Asia using 5 key indicators; namely self-expression, learning needs, leisure \& entertainment, escape from real life and killing time, with an analysis from the demographic perspective of the respondents including gender, education, country and age. The results of the survey show that gratifications obtained in the digital media in these countries were not correlated with gender and education, but it was different or correlated with country and age of the respondents.

(c) 2020 by the authors; licensee Growing Science, Canada

\section{Introduction}

There are plenty of studies conducted on the digital media, including the gratifications element of the digital media. However, studies on the issue that focus on the Southeast Asian market are still very rare. Southeast Asia is the home for more than half a billion populations, with vast growing economy and relatively young population. This is a huge market with very promising potential for digital business, including the media. The digital media business has been the spotlight in the media industry in the last few years, contributed by the enormous growth of the big digital video companies such as Netflix, YouTube, etc. Netflix currently has about 150 million paying subscribers worldwide according to CNN (Pallotta, 2019), while YouTube has more than 1 billion users (Cook, 2019). The usage of media platform is closely associated with the obtained gratifications (OG) by the users of the media (Katz, et. al., 1974). The gratifications obtained from consuming the media will have impact on other variables, as many studies have shown. This paper will dig deeper into the gratifications obtained by digital media users in four countries in Southeast Asia. Respondents of this study are taken from four countries in Southeast Asia: Indonesia, Malaysia, Singapore and Philippines. The respondents in these countries are relatively different to the ones from other parts of the world. This region is unique in terms of the demography, compared with, for example, Europe or the US. Majority of the population are younger and are very attached to the digital services (as will be shown by the findings later). These four countries represent of more than 400 million population, according to ASEAN UP research (2019). According to Google, as quoted by Medium (2019), population of these countries (and other countries in Southeast Asia) spend more time using internet mobile services than those in Europe or Eastern Asia. The results of this study shall be useful to understand more about the profile of the digital media users in the region and how any digital media (both the media companies that operate in each individual country and those operating cross-country) can approach each of the audience group.

\footnotetext{
* Corresponding author.

E-mail address: hendyliem@yahoo.com (H. Kasim) 


\section{Literature Review}

Obtained gratification (OG) is an element studied in the Uses and Gratifications Theory (UGT), which was first introduced by Herzog in 1944 to measure the impact of radio during that time (Luo, 2002). It was then being made popular by study from Katz et al. (1974). Basic assumption of the UGT is that the audience is considered as an active entity involved in the usage or consumption of media. They are no longer considered as "helpless" audience who will consume everything available for them. They will actively seek in order to satisfy their needs. This has more relevancy especially when the number of media grows, thus it leaves audience with abundance of choices. Baran and Davis $(2009 ; 232)$ describe it as followed: "People put specific media and specific media content to specific use in the hopes of having some specific need or set of needs gratified". West and Turner (2010) suggest that the UGT was actually an extension of the Needs and Motivation Theory by Abraham Maslow in 1954, which argues that people actively look to satisfy their needs based on a hierarchy. Katz, et al. (1974) argued that the audiences actively choose specific media to fulfill their needs and justify their choice, and that other consumers might choose the same media, but for entirely different goals. It is also argued that audience is goal directed and is aware of their needs. This means that the audience or consumers are considered as the active agents in the communication process. The consumers of the media are actively trying to find the media that best suits their need or Sought Gratification. The UGT implies that audiences are active in choosing whichever media to fulfill their needs. This theory emphasizes on humanly approach in the way media is being portrait. Humans are considered as independent and have freedom in how to use media. This theory is not interested in what media do to people, but rather in what people do to media. Usage or consumption of media is driven by certain motives. The UGT according to Katz et al. (1974) is based on some basic assumptions. Audience is considered as active. They use media with a certain motives and objectives to be achieved. Within the process of mass communication, the majority of the initiative in linking gratification and choice of media lies within the members of the audience. The media does compete with other sources (including non-media) as the source of satisfaction. In terms of the methodology, many of the objectives of the use can be derived from data that is supplied by individual audience members themselves. Judgments of value about the cultural significance of the mass communication should be suspended during the time when the orientations of the audience are being explored. McQuail (2010) proposed that the objectives for media use could be classified into five types of uses. He proposed that the audience uses media because he or she wants to (1) be informed or educated, (2) identify with characters of the situation in the media environment, (3) have simple entertainment, (4) enhance social interaction, and (5) escape from the stresses of daily life.

Consumer's gratification level after using the media should be measurable. Mowen and Minor (2002) define consumer satisfaction as the overall attitudes shown by consumer toward goods and services, after they obtained and used them. The measurement in this UGT context is often described as Gratification Sought (GS) and Obtained Gratification (OG). Gratification Sought is the satisfaction that is sought, wanted or needed when a consumer decides to use a certain media. GS can also be understood as the basic reason of why a consumer consumes a media and as the effort to seek satisfaction upon a specific need. Consumer willingness to choose or not to choose a certain specific media or content is influenced by certain reasons, which are based on the motivation of fulfillment of needs. By having certain expectations, a media consumer is deemed to have certain objectives to be accomplished before they turn on a certain media or content. Therefore, it can be concluded that GS is an expectation of a media consumer in consuming a certain media. This initial expectation is expected to be fulfilled by the media. In this research, the GS refers to the expectations or objectives sought by the consumers toward the digital content. Obtained Gratification (OG) is a set of satisfaction obtained by an individual upon the fulfillment of certain needs after that particular individual consuming the media. Consumers will make comparison between what they seek in the GS and what they get in actual reality within the OG. This will eventually determine the consumers' judgment or perception toward the media or content that they consume. In the context of this research, the OG refers to the gratifications or satisfaction that the consumers obtain through the consumption of digital video contents.

\subsection{Other Research on $U G T$}

The UGT has gained its "second life" in recent years because of the massive and rapid development of communications and media technology. The development of the technology in the field of communications and media in particular, have brought more relevancy for the Uses and Gratifications Theory. Consumers have more choices and gained much more control in terms of what media they would like to consume. Malik et al. (2016) studied the uses and gratifications of digital photo sharing on Facebook. The research identified six different gratifications, namely Affection, Attention Seeking, Disclosure, Habit, Information Sharing, and Social Influence. The main findings in this study were: (1) Age was in positive correlation with disclosure and social influence gratifications; (2) Gender differences were identified among habit and disclosure gratifications; (3) Number of photo shared was negatively correlated with habit and information sharing gratifications. Magsamen-Conrad and Greene (2015) studied the life-span difference for older adults in the uses and gratifications of tablets device. This study extends the UGT by examining the uses and gratifications of a new technological device, the tablet computer, and investigating the differential uses and gratifications of tablet computers across the life-span. The study suggested there were four main uses of tablets: (1) information seeking, (2) relationship maintenance, (3) style, (4) amusement and killing time, and (5) organization. The study discovered that there are differences among the five main uses of tablets across the life-span, with older adults using tablets the least overall. 
Lin (2014) from National University of Singapore (NUS) researched the effects of gratifications on intention to read citizen journalism news with the mediating effect of attitude. The effects of gratifications on attitude and intention were examined. The indirect effects of gratifications on intention to read news through the interpretation of affection that users experienced were also examined. The research shows that all gratifications, except for escape, have direct effects on attitude. However, none of the gratifications has a direct effect on intention. It also shows that attitude mediated the path between the effects of all gratifications and intention. Kang (1999) explored the role of media uses and gratifications in multimedia cable adoptions. The research was a thorough analysis of the customers' view on the traditional versus new media. The result of this study revealed positive relationships between perceived motives associated with the use of both traditional television and emerging multimedia cable services. Punyanunt-Carter et al. (2017) investigated the relationships among college students' satisfaction, addiction, needs, communication apprehension, motives, and uses \& gratifications with the social media application Snapchat. Results indicated that college students were satisfied using Snapchat. Findings showed that there was a significant relationship between participants' needs (entertainment and functional) with Snapchat addiction, intensity and exhibitionism. Further, there was a relationship between participant's needs (entertainment and functional) with communication apprehension.

\subsection{Difference Between Gratification and Satisfaction}

There has sometimes been a confusion or mixed up between these two terms. Gratification and satisfaction are not the same concept, although there are some similarities shared. Gratification concept referred by this research is the concept discussed earlier in this dissertation. It is a more specific concept applied to the media studies, and in which there are comparisons and tests between gratification sought and gratification obtained by the audience from the media that they consume. This is actually a much more specific concept from the bigger concept of satisfaction. Palmgreen and Rayburn (1985) explained the difference between the two concepts. They acknowledged that these two concepts are sometimes puzzling due to the popularity and utility of the satisfaction concept in other social science areas. Satisfaction is a key concept in areas such as organizational psychology, communication and marketing. The terms of "media satisfaction" is rarely used or researched, however they also acknowledged that media gratification is a part of media satisfaction. Gratification concept goes deeper into the details of specific attributes related to the media consumption by the consumers, as described by the UGT. Satisfaction, on the other hand, has wider concepts, as explained by Oliver (1981) as the emotional reaction following a disconfirming experience. As the conclusion, Palmgreen and Rayburn (1985) posit satisfaction with the media to be determined partially by the gratification perceived to be obtained from these media as products.

\section{Research Method}

We gather information through the sampling of questionnaire from 282 respondents based in Indonesia, Malaysia, Singapore and the Philippines, with the age starts from 15 years old. They were connected to Internet and were users of digital media. Of all the respondents, there were only 250 samples eligible to be processed, of which $47.6 \%$ were male and $52.4 \%$ were female. Samples were filtered by the condition that the respondent should be a user of digital media (one of YouTube, Netflix, etc.). Sampling was accomplished using disproportionate stratified random sampling technique. Collected samples were processed using SPSS, and were checked for validity and reliability, as the preliminary process. ANOVA will be the tool used for the analysis on the hypothesis whether there are any differences in the obtained gratifications among different demographic traits. The next step will be to do post-hoc Tukey HSD or homogeneity test to find out more details on the differences of the demographic traits (if there is any).

\section{Results and Discussions}

Table 1 below shows the result of the reliability test, which passed the minimum Syandard of 0.6 for Cronbach's alpha (Nunnaly, 1967).

Table 1

Reliability Test

\begin{tabular}{ccc}
\hline Variable & Cronbach's Alpha & Items \\
\hline Obtained Gratification (OG) & 0.674 & 5 \\
\hline
\end{tabular}

Table 2 below presents the result of the validity test of the indicators used. For a sample more of than 250 respondents, the minimum acceptable score for Corrected Item-Total Correlation is 0.3 . The result below shows that the indicators range from .422 to .461 , therefore they can be deemed valid. Next we do analysis with ANOVA. Initial hypothesis will be established that there will be no difference of the variable results among the demographic attributes. The ANOVA calculation will determine if the initial hypothesis or the alternative hypothesis to be accepted. The test is deemed significant if the sig. score is $\leq$ 0.05. That way, the initial hypothesis $\left(\mathrm{H}_{0}\right)$ is rejected and the alternative hypothesis $\left(\mathrm{H}_{1}\right)$ is accepted. The result is shown in Table 3 . 
Table 2

Validity Test

\begin{tabular}{lcccc}
\hline Scale Mean if Item Deleted & \multicolumn{2}{c}{ Scale Variance if Item Deleted } & Corrected Item- Total Correlation & Cronbach's Alpha if Item Deleted \\
\hline OG1 : Self Expression & 15.60 & 4.594 & .430 & .622 \\
OG2: Learning Need & 15.16 & 4.927 & .450 & .623 \\
OG3: Leisure and Entertainment & 14.90 & 4.829 & .461 & .617 \\
OG4: Escape from real life & 15.67 & 3.821 & .446 & .623 \\
OG5: Killing time & 15.36 & 4.063 & .422 & .630
\end{tabular}

Table 3

ANOVA on Gender, Education, Country and Age

\begin{tabular}{|c|c|c|c|c|c|c|}
\hline \multicolumn{3}{|c|}{ Sum of Squares } & df & Mean Square & $\mathrm{F}$ & Sig. \\
\hline \multirow[t]{3}{*}{ Gender } & Between Groups & .058 & 1 & .058 & .223 & .637 \\
\hline & Within Groups & 63.927 & 248 & .258 & & \\
\hline & Total & 63.984 & 249 & & & \\
\hline \multirow[t]{3}{*}{ Education } & Between Groups & .711 & 2 & .355 & 1.387 & .252 \\
\hline & Within Groups & 63.274 & 247 & .256 & & \\
\hline & Total & 63.984 & 249 & & & \\
\hline \multirow[t]{3}{*}{ Country } & Between Groups & 8.102 & 3 & 2.701 & 11.889 & .000 \\
\hline & Within Groups & 55.882 & 246 & .227 & & \\
\hline & Total & 63.984 & 249 & & & \\
\hline \multirow[t]{3}{*}{ Age } & Between Groups & 9.557 & 3 & 3.186 & 14.399 & .000 \\
\hline & Within Groups & 54.427 & 246 & .221 & & \\
\hline & Total & 63.984 & 249 & & & \\
\hline
\end{tabular}

Based on the above table, hypotheses and conclusions can be established and drawn:

\subsection{Gender}

$\mathrm{H}_{0}$ : There is no significant difference on OG between different genders.

$\mathrm{H}_{1}$ : There is a significant difference on OG between different genders.

According to Table 3, there is no evidence to reject the null hypothesis when the level of significance is five percent. Therefore, it can be concluded that there is no significant difference on OG between different genders.

\subsection{Education}

$\mathrm{H}_{0}$ : There is no significant difference on OG among people with different educational background.

$\mathrm{H}_{1}$ : There is a significant difference on OG among people with different educational background.

Based on the results of Table 3, there is no evidence to reject the null hypothesis when the level of significance is five percent. Therefore, it can be concluded that there is no significant difference on OG among people with different educational background.

\subsection{Country}

$\mathrm{H}_{0}$ : There is no significant difference on OG among people from different countries.

$\mathrm{H}_{1}$ : There is significant difference on $\mathrm{OG}$ among people from different countries.

The results of Table 3 indicate that there was no evidence to reject the null hypothesis when the level of significance is five percent. Therefore, it can be concluded that there is significant difference on OG among people from different countries.

\subsection{Age}

$\mathrm{H}_{0}$ : There is no significant difference on OG among different age groups.

$\mathrm{H}_{1}$ : There is significant difference on OG among different age groups.

Finally, it can also be concluded that there is significant difference on OG among different age groups.

After the ANOVA, we continue the analysis with Tukey HSD (homogeneity test). This is a continuance test to provide more detail information and analysis as a continuance from ANOVA test. ANOVA tells us whether or not that there is any significant difference between the demographic characteristics, but it does not show where exactly the differences lies. To find out the exact reason where the differences lies, Tukey test was performed to support this. Table 4 below provides the details. 
Table 4

Homogeneity Test

\begin{tabular}{|c|c|c|c|c|}
\hline \multirow[t]{2}{*}{ 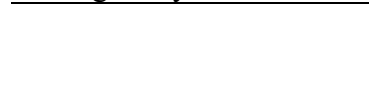 } & \multicolumn{4}{|c|}{ Subset for alpha $=0.05$} \\
\hline & $\mathrm{N}$ & 1 & 2 & 3 \\
\hline \multicolumn{5}{|l|}{ Education } \\
\hline c. Master degree or higher & 49 & 3.7265 & & \\
\hline a. High school or lower & 50 & 3.8560 & & \\
\hline b. Bachelor degree & 151 & 3.8623 & & \\
\hline Sig. & & .286 & & \\
\hline \multicolumn{5}{|l|}{ Country } \\
\hline Singapore & 80 & 3.6875 & & \\
\hline Malaysia & 53 & 3.7057 & & \\
\hline Indonesia & 67 & 3.8657 & & \\
\hline Philippines & 50 & & 4.1640 & \\
\hline Sig. & & .172 & 1.000 & \\
\hline \multicolumn{5}{|l|}{ Age } \\
\hline 46 and Above & 64 & 3.5469 & & \\
\hline $36-45$ & 55 & & 3.7891 & \\
\hline $26-35$ & 71 & & 3.9211 & 3.9211 \\
\hline $15-25$ & 60 & & & 4.0800 \\
\hline Sig. & & 1.000 & .402 & .239 \\
\hline
\end{tabular}

This test is performed for variables that have more than 2 categories; therefore, there is no analysis on gender in this test as it only shows 2 categories (male and female). The test above shows consistency with ANOVA that there is no difference of OG in the education levels. It means OG is not depending on the respondent's level of education. But there are differences in OG based on countries and age. The table shows that the difference lies with the Philippines. This country scores a statistically significant difference compared with the other three ones. Indonesia, Malaysia and Singapore are deemed to be relatively similar (no statistically significant difference). In terms of the age group, it shows that there were 3 different groups of OG. Age group of 46 and above is deemed to have the lowest OG, and the youngest group (15-25) scores the highest. Age group of 26-35 and 36-46 are in the same group, with those in 26-35 also have similarities with 15-26.

\section{Conclusion}

Based on the results above, several conclusions can be drawn. First, gender does not determine the differences in OG. The ANOVA test shows sig. level at .637 confirms that the same scenario like gender also applies for education level. The education level does not determine the differences in the OG. Third, the OG differs according to the country in this study. Detail analysis from post hoc test shows that the difference lies in the Philippines, which is classified as different subset to the other 3 countries. Indonesia, Malaysia and Singapore are deemed to be relatively the same. OG also differs according to age group. There are 3 subsets in the OG according to the age group: Age 46 and above has maintained the lowest OG, and age 15-26 has the highest one. It can be concluded from the post hoc test that the younger the age of the respondents, the higher the OG level. This is also supported by the result of respondents age 26-35 and 36-45. The post hoc test has shown the result as age group $45 \&$ above $<36-45<26-35<15-26$. The result in this research supports the finding by Malik (2016) that found that age was correlated with gratifications. But the same research also found that gender was also correlated with gratifications, which is the opposite from this research. The findings about age in this research supports the finding from Magsamen-Conrad and Greene (2015), where age plays role in gratifications. Based on the results in this research, digital media practitioners and researchers can use this research as an input and consideration when approaching consumers based in the countries involved in this research. Considerations must be taken when studying and approaching consumers that are different, based on its country and the age group.

\section{References}

ASEAN UP. (2019). Southeast Asia Digital, Social and Mobile 2019. Retrieved from https://aseanup.com/southeast-asiadigital-social-mobile/

Baran, S. J., \& Davis, D. K. (2009). Mass communication theory: foundations, ferment, and future (6th ed.). Boston, MA: 
Wadsworth.

Cook, S. (2019). Youtube Statistics and Facts. Downloaded on July 8, from https://www.comparitech.com/tv-streaming/youtube-statistics/

Kang, M. E., \& Atkin, D. J. (1999). Exploring the role of media uses and gratifications in multimedia cable adoption. Telematics and Informatics, 16(1-2), 59-74.

Katz, E., Blumber, J. G., \& Gurevitch M. (1974). Uses and Gratifications Research. The Public Opinion Quarterly, 37(4), 509-523.

Lin, J. (2014). The effects of gratifications on intention to read citizen journalism news: The mediating effect of attitude. Computers in Human Behavior, 36, 129-137.

Luo, X. (2002). Uses and gratifications theory and e-consumer behaviors: a structural equation modeling study. Journal of Interactive Advertising, 2(2), 34-41.

Magsamen-Conrad, K., \& Greene, K. (2014). Technology addiction's contribution to mental wellbeing: The positive effect of online social capital. Computers in human behavior, 40, 23-30.

Malik, A., Dhir, A., \& Nieminen, M. (2016). Uses and gratifications of digital photo sharing on Facebook. Telematics and Informatics, 33(1), 129-138.

McQuail, D. (2010). Mass communication theory: an introduction. London: Sage Publications.

MEDIUM. (2019). Southeast Asia Mobile Internet Usage Increasing Dramatically. Retrieved from https://medium.com/financex/southeast-asia-mobile-internet-usage-increasing-dramatically-bb63266affb5

Mowen, J. \& Minor, M. (2002). Consumer Behavior (5 ${ }^{\text {th }}$ ed.). McGraw-Hill Education.

Nunnaly, J.C. (1967). Psychometric Theory. New York: McGraw-Hill.

Oliver, R. L. (1981). Measurement and Evaluation of Satisfaction Procesesses in Retail Settings. Journal of Retailing, 57, 2548.

Pallotta, F. (2019). Netflix Added Record Number of Subscribers, But Warn of Tougher Times Ahead. Downloaded on July $8^{\text {th }}$, from https://edition.cnn.com/2019/04/16/media/netflix-earnings-2019-first-quarter/index.html

Palmgreen, P. and Rayburn, J.D. (1985). A Comparison of Gratification Models of Media satisfaction. Communication Monographs, 52(4), 334-346.

Punyanunt-Carter, N. M., De la Cruz, J. J., Wrench, J. S. (2017), Investigating the relationship among college students' satisfaction, addiction, needs, communication apprehension, motives, and uses \& gratifications with Snapchat. Computers in Human Behavior, 75, 870-875.

West, R. \& Turner, L. (2007). Introducing Communication Theory. McGraw Hill.

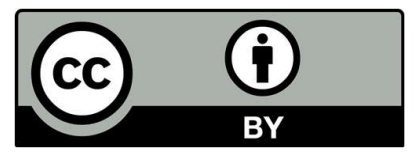

(C) 2020 by the authors; licensee Growing Science, Canada. This is an open access article distributed under the terms and conditions of the Creative Commons Attribution (CCBY) license (http://creativecommons.org/licenses/by/4.0/). 